\title{
Dignidad y libertad. Una relectura de Juan 8:31-47 frente al delito del tráfico de mujeres con fines de explotación sexual.
}

\author{
Dignity and freedom. \\ A rereading of John 8:31-47 against the crime \\ of trafficking of women for the purpose of sexual exploitation.
}

\begin{abstract}
Resumen
A partir de las palabras de una mujer que fue víctima de trata y que pudo liberarse, creando conciencia para sí y para quienes buscan comprometerse en la abolición del sistema prostituyente de la trata de personas, proponemos una relectura del mensaje de Jesús sobre la dignidad y la libertad que como cristianos estamos llamados a construir.
\end{abstract}

Palabras clave: dignidad; libertad; trata; prostitución; mujer

\begin{abstract}
Based on the words of a woman who was a victim of trafficking and who was able to free herself, creating conscience for herself and for those who seek to commit themselves to the abolition of the prostitution system of human trafficking, we propose a rereading of Jesus's message about dignity and the freedom that we as Christians are called to build.
\end{abstract}

Key words: dignity; freedom; human trafficking; prostitution; woman

\section{Introducción}

Carta abierta a los expertos y expertas en trata.

No me dicen nada sobre mí cuando hablan de "trata".

Me dicen mucho de la doble moral de ustedes y del maquillaje y del uso que hacen de nosotras.

\footnotetext{
${ }^{1}$ Sandra Nancy Mansilla. Argentina, laica, profesora de teología por la Pontificia Universidad Católica Argentina, especializada en estudios bíblicos. Desempeña la docencia teológica en diversas instituciones. Colabora especialmente en la formación de promotores bíblicos, agentes de pastoral; asesora y anima espacios de Lectura Popular de la Biblia. Miembro de la Comunidad Teológica "Rajab" y del Equipo Género y Biblia, en Argentina (correo electrónico: snmansilla@ gmail.com).
} 
Este gran circo al que llaman

"lucha contra la trata"

y del que ustedes son dueños,

me dice mucho sobre la creación

y fortalecimiento de una nueva "zona roja"

y de ese hacer para no cambiar nada.

Así como sostengo que debatir la prostitución sólo entre putas

es sostener nuestra vulnerabilidad

y exculpar al fiolo y al prostituyente,

también les digo:

dejen de hollywoodensear el tráfico

de mujeres para explotación sexual.

Sabemos y somos conscientes, todas y todos de:

Que es el hambre la que nos "trata",

Que es la falta de trabajo la que nos "trata",

Que es la falta de un hogar, la que nos "trata",

Que es la falta de educación la nos "trata".

Por eso las putas no necesitamos más leyes, talleres, forros, necesitamos que las que hay se cumplan.

Necesitamos un shock de políticas sociales serias,

para nosotras y nuestras familias.

Necesitamos que se visibilice,

persiga y criminalice al prostituyente, torturador, que vive en sus casas.

Necesitamos que nos saquen un poco las manos de encima.

Necesitamos que ustedes trabajen en sus hipocresías y mentiras.

Traten (SÁNCHEZ, 2018, pp. 46-47).

Sonia Sánchez es una mujer que vivió algunos años de su vida de la prostitución, o mejor dicho el sistema prostituyente vivió de ella. Pudo salir de esa realidad, y hoy se considera una sobreviviente.

Actualmente vive en Buenos Aires y, con la autoridad que le otorga su experiencia, enseña a través del relato de su vida, concientizando a otros sobre los laberintos y trampas del sistema que la tuvo cautiva bajo un campo de concentración a cielo abierto, tal como ella lo expresa.

La plaza, la calle, la comisaría continúan siendo lugares de tortura y muerte silenciosa de tantas compañeras que Sonia nombra con sus nombres, apodos y anécdotas de terror. Ella está convencida de que, así como el silencio fue un arma para el sometimiento, ahora la palabra ha de ser su aliada para la denuncia. Una palabra llamada a ser pronunciada en público y en sentido literal, sin metáforas ni disimulos, en favor de otras que no pueden hacerlo, aquellas mujeres compañeras que aún se encuentran 
sometidas por una sociedad que las ignora, las invisibiliza, las olvida, o bien las reglamenta en protocolos, en zonas rojas y hasta las sindicaliza.

Sonia dice que ser puta es vivir con el engaño de creer que esta mujer tiene el poder y la libertad de vender su cuerpo, cuando la triste verdad que no puede reconocer es que un otro la compra-vende: el fiolo, el marido, el amante; en verdad nada a ella pertenece.

Sonia ahora habla mucho del cuerpo, porque una mujer en estado de prostitución no puede hacerlo. Hay un gran silencio acerca del cuerpo propio entre las prostitutas, porque la palabra está exiliada del cuerpo de la prostituta. Son otros los que lo nombran, lo califican y lo cotizan. Y en esa escisión entre el cuerpo y la palabra de la mujer prostituida opera el sistema, su dominación de intercambio, de transacción, de prácticas prostituyentes con nombres de fantasía: "media francesa", "una francesa", "un completo", fantasía para referirse a qué partes del cuerpo se tiene derecho de acceder según el precio acordado. Un cuerpo que seccionado en partes ya deja de ser un cuerpo para ser una cosa, un artefacto. Y a ese cuerpo, entonces, fragilizado se lo incorpora a un sistema corporativo de intercambios y acuerdos implícitos acerca del valor, del estatus y del poder de unos cuerpos sobre otros.

Donde Sonia habla, ella instala una voz disruptiva en el escenario de especialistas sobre trata y prostitución. Disruptiva digo, porque ella ha pasado por la experiencia, cosa que la mayoría de los especialistas no han hecho. Su palabra truena con autoridad porque ella conoce bien la trama que sostiene el maldito sistema. En la urgencia de su voz ojalá reaccionemos, porque alguna vez tengamos dudas y sospechemos de todo aquello que repetimos y creemos conocer acerca de este mundo que nos es tan ajeno.

Dignidad y libertad en Sonia fueron lecciones aprendidas desde el cuerpo y la palabra, desde la experiencia y el discurso, deconstruidos y reconstruidos. Sus palabras hablan desde una verdad puesta al desnudo y desde una libertad conquistada en el riesgo. La vida de Sonia, como tantas otras, irrumpe como la mujer que se erige en medio de la escena de los varones, del relato del Juan 8,1-11; como un relato desubicado, extraño, disruptivo, que nos interpela en la posible hermenéutica del mensaje de Jesús hablando a los creyentes, y no tantos, del resto del capítulo 8. Así, pues, con la palabra de Sonia en el telón de fondo haremos el esfuerzo por decir algo nuevo sobre la dignidad y la libertad, a partir de la lectura de Juan 8,31-47 ante el escándalo del tráfico de personas para fines de explotación sexual.

"Si os mantenéis en mi Palabra, seréis verdaderamente mis discípulos, y conoceréis la verdad y la verdad los hará libres" (vv. 31-32).

La investigación de los últimos años ha llegado al consenso de que el evangelio de Juan, así como otros textos, ha sido compuesto no de una sola vez, sino sobre la tarea de una redacción larga y compleja. La perí- 
copa de la adúltera (Cf. 7,53-8,11), que ciertamente no pertenece al texto original, da cuenta de tales anomalías en la sección de los capítulos 7-8 en el escenario del Templo de Jerusalén, durante la fiesta de los Tabernáculos. Las soluciones propuestas desde la teoría de la redacción o de las fuentes y ediciones múltiples son esfuerzos para valorar una ardua obra redaccional, y tal como concluye Stef van Tilborg "es necesario decir que el evangelio muestra una gran unidad de inspiración teológica que plasma tanto la articulación sincrónica de la obra como su proyecto global" (2005, p.7).

El curioso tratamiento de esta perícopa nos ha llevado a indagar algo en la historia de la interpretación para saber que el pasaje es reconocido por Papías², discípulo de Juan, de modo que el relato es conocido ya en el siglo I. Por otra parte, Agustín de Hipona, en Tratados sobre el Evangelio de Juan, es el mayor defensor de la genuinidad del pasaje: " $Y$ algunos de poca fe, o, mejor dicho, enemigos de la verdadera fe, temiendo, según creo, que se conceda a sus mujeres la impunidad en el pecar, arrancaron de sus códices aquella escena en que el Señor perdonó a la adúltera ${ }^{3}$. Como hace notar HENDRIKSEN (1981), "íntimamente relacionado con esto está el hecho de que el ascetismo desempeñó un papel importante en la era sub apostólica. De ahí que no se pueda descartar totalmente la sugerencia de que esta sección (7:53-8:11) formaba en otro tiempo parte del Evangelio de Juan para ser quitada del mismo más tarde" (HENDRIKSEN, 1981, p. 299).

Aquella escena, que la mayoría de los comentarios considera extrapolada y extraña para el evangelio de Juan, por ser omitida en los códices más antiguos y desplazada por otros, porque de-ella-no-se-habla, sin embargo, nos mira desde el textus receptus y enriquece el sentido del capítulo en su vertiente retórica. En tal sentido, no abordaremos en este estudio la crítica textual de tales pasajes, sino que aplicaremos una lectura del texto canónico en su redacción final, según el abordaje del análisis sincrónico, en particular del método retorico. De tal manera que el dialogo de Jesús de Juan 8,31-47 ofrezca también un sentido referido a la escena de la mujer sometida a juicio de los vv. 1-11, en tanto situación retórica, es decir una situación que da pie a tales diálogos de Jesús y sus interlocutores.

¿Acaso hoy ciertas situaciones disruptivas de la vida de las personas y, en particular, de las mujeres víctimas de trata no están exigiéndonos hablar-de-ciertas-cosas, a tiempo y destiempo, como para fortalecer nuestra teología en clave de liberación? Con esta inquietud voy a concentrarme en el estudio de los vv. 31-47, sin perder de vista aquel marco redaccional para volver posteriormente sobre él. De este modo la expresión "la verdad os hará libres" será una promesa que nos llena de esperanza y audacia por

\footnotetext{
${ }^{2}$ Según consta con Eusebio de Cesarea en: Historia Ecclesia. III. 39, 17 Disponible en: http://escrituras.tripod.com/Textos/HistEcl03.htm Visitado el 30 de Jun de 2019.

${ }^{3}$ Como nuevamente puede ver en Agustín. De adulterinis conjugiis, II, 7. Disponible en: http:// www.augustinus.it/spagnolo/connubi_adulterini/connubi_adulterini_2_libro.htm Visitado el: 30 de Jun de 2019.
} 
su entera realización, como una luz que lucha por no apagarse y que lleva en sí misma la fuerza para continuar iluminándonos en las peores oscuridades.

\section{Tres diálogos in crescendo}

El pasaje se ubica en un momento álgido en la escena del evangelio. Ni más ni menos que la presentación del Yo soy de Jesús, la revelación más explícita y, a su vez, la más controvertida. La sección que nos interesa es un dialogo que está precedido por otros dos, que estructuran el capítulo 8 , y que prosiguen a la gran revelación del v. 12 Yo soy la luz del mundo; el que me siga no caminará en oscuridad, sino que tendrá la luz de la vida.

A. 8,13-20 Jesús y los fariseos

B. 8,21-30 Jesús y los judíos

C. 8,31-59 Jesús y los judíos que habían creído en el

a. 31-38 de la esclavitud a la libertad

b. 39-47 ¿Es vuestro padre Abraham -o Caín-? ¿Dios o el demonio?

c. 47-59 Jesús es mayor que Abraham

v.31a: "Decía pues, a los judíos que habían creído en él".

Se trata posiblemente de aquellos que se quedaron a escucharle, impresionados por su acción y su argumento. A ellos Jesús les pondrá una condición, si os mantenéis en mi Palabra, seréis realmente mis discípulos (v.31b). Para Jesús, al parecer, no alcanza con tener una actitud receptiva hacia su palabra, sino que es necesario también ponerla en práctica, es decir hacerla vida y permanecer en ella, lo cual significa aliarse por completo a Jesús, porque el verbo $\mu \varepsilon v o$, permanecer, tiene en Juan el sentido de comunión o incluso de inmanencia (15,4-7; 1Jn 4,16). Por lo tanto, se trata de una identificación plena, que caracteriza al verdadero discípulo de Jesús, reforzado por el uso del pronombre posesivo E $\mu$ o (lit. la Palabra mía). Es decir, no se trata de una palabra cualquiera, sino la palabra de Jesús, la que Él les daba. En esa conjunción emerge la verdad que libera, es decir la profecía que transforma, el verdadero discipulado del cual la garantía es que conoceréis la verdad, y la verdad os hará libres (v. 32). Seguir a Jesús, pues, no es un ejercicio de doctrinas, ni leyes, ni mandamientos que hay que saber o repetir; seguir a Jesús consiste en actuar con él y como él, para que no haya más opresión, ni opresores ni oprimidos.

La fe en Jesús no es una religión, sino una identificación personal e íntegra de adhesión y seguimiento. Así, pues, verdad y libertad se nutren recíprocamente ya que la verdad se manifiesta y crece cuando actúa liberando, tal como Jesús lo hace. Podemos decir, entonces, que no existe teología cristiana verdadera si esa teología no produce liberación. Seguramente no alcanzamos todavía la liberación que anhelamos, porque nece- 
sitamos comprender y vivir con más intensidad y compromiso el mensaje de Jesús, haciéndolo más real y efectivo -según la medida de nuestra feen las situaciones que claman hoy por esa liberación.

v. 33: Ellos le respondieron: "Nosotros somos descendencia de Abraham y nunca hemos sido esclavos de nadie. ¿Cómo dices tú: 'Os haréis libres'?"

Puede suceder que damos por sentado que ya hemos cumplido nuestra parte, pensando como los judíos del relato que somos linaje de Abraham porque tenemos claras las causas y los poderes que intervienen en el sistema de opresión. Pero esa razón se convierte en palabra muerta si no ponemos en acto esa dignidad. Puede suceder que nuestra dignidad de creyentes sea un gran título anquilosado si es que no se convierte en verbo, en acción de dignificar. Cualquier título pierde legitimidad si no se traduce en acciones, y tan así puede sucedernos también a los cristianos. En ese caso, nuestra omisión estaría poniendo al descubierto nuestra hipocresía, nuestra corrupción; en términos bíblicos nuestro pecado, porque "todo el que obra pecaminosamente es un esclavo" (v. 34), que ni siquiera ha logrado la libertad para sí mismo. Puede suceder, según expresa la sentencia final precedida por un rotundo Amén, Amén, que llamarnos tranquilamente cristianos en un continente marcado por la opresión, la corrupción y la indiferencia se vuelva en nuestra contra para acusarnos, cuando llamándonos cristianos no ponemos en acto la verdad y la libertad que caracteriza nuestra fe. De hecho, el esclavo puede ser echado en cualquier momento de la casa, no así los hijos que permanecen - $\mu \varepsilon v o-$ en la Palabra del Hijo.

v. 36: Si el Hijo los hace libres, ustedes serán realmente libres,

La verdadera libertad se nos manifiesta en Jesús y en nadie más. En Él reconocemos la suma dignidad que estamos llamados a realizar y la cual debemos construir para toda humanidad y, en ella, para toda la creación, en términos paulinos. Jesús es, pues, la garantía y la medida entera de nuestra dignidad y de nuestra libertad, para nosotros y para toda creatura. En Cristo somos liberados de toda falsa dignidad y adoptados como hijos en la dignidad del Hijo, en eso consiste la verdad a la adhiere la fe cristiana y por la que somos definitivamente liberados para operar liberación en su Nombre.

v. 37: Ya sé que ustedes sois descendencia de Abraham; pero tratáis de matarme, porque mi Palabra no encuentra acogida en vosotros.

Ante sus interlocutores, que quieren matarle, Jesús reconoce en el sentido histórico y físico, que todos ellos son descendencia de Abraham, lo que incrementa la perversidad de sus propósitos y la esclavitud manifiesta de un corazón pecaminoso, quizá por eso no los llama hijos de Abraham

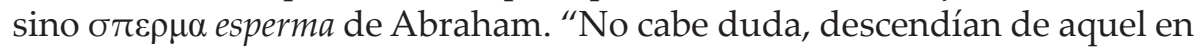
quien se inició la nación de Israel, pero no son espiritualmente sus descendientes porque la fe de Abraham está ausente de sus corazones y no son conducidos por ella" (PÉREZ MILLOS, 2016, P. 866). 
Quienes quieren matar a Jesús hoy son aquellos que desde la esclavitud de su corrupción oprimen la Verdad, la de una dignidad que todavía no hemos alcanzado más que en promesa. Permanentemente estamos amenazados de muerte, incluso hasta por quienes teniendo algún poder dilatan la puesta en acto de la verdad, porque la Palabra no encuentra acogida. El clamor es urgente y brota de los sótanos clandestinos donde se ejerce la opresión sobre los más débiles, por ser pobres, migrantes, explotados, vendidos, traficados, prostituidos, olvidados.

v. 44: Vosotros sois de vuestro padre el diablo y queréis cumplir los deseos de vuestro padre. Este era homicida desde el principio, y no se mantuvo en la verdad porque no hay verdad en él: cuando dice la mentira dice lo que le sale de dentro, porque es mentiroso y padre de la mentira.

En este momento la sentencia de Jesús se radicaliza diversificando dos proyectos, el de los hijos de Dios y el de los hijos del diablo. El diablo, asesino desde el origen y hasta el final. Enemigo de la vida, de la verdad, de la dignidad y de la libertad que buscamos los hijos de Dios. ¿Qué más claridad necesitamos para entender el lugar que estamos llamados a ocupar como verdaderos creyentes ante un plan sistemático de secuestro, explotación prostituyente y muerte de tantos y tantas hermanos y hermanas víctimas del crimen de trata y explotación sexual, y en ellos de toda dominación egoísta de cuanta creatura es usada como objeto de consumo y descarte?

\section{Libertad y verdad amenazadas}

Recordamos nuevamente el contexto donde ocurren todas estas escenas y diálogos que nos trae el evangelio de Juan, la fiesta de los tabernáculos, la que recuerda al pueblo reunido en el desierto, recibiendo la ley que rescata de la esclavitud para hacer hijos de Dios, pueblo libre al servicio de la vida. En una fiesta donde las luces son el signo principal, Jesús se presenta como la Luz verdadera. El hilo de la narración, no obstante, desemboca en el rechazo y nos muestra a los adversarios de Jesús buscando una trampa para acusarle y matarle. ¿Acaso situaciones de suma gravedad como las que diariamente nos dejan sin palabras, situaciones que delatan la crueldad y la deshumanización de un sistema criminal no desafían la tenacidad de nuestros estudios y reflexiones a fin de dejarnos sin argumentos? ¿Ante cada víctima, acaso no sentimos la desazón de retirarnos entre cocotazos (v. 59) para no ser del todo derrotados a fin de volver más tarde con otros argumentos más convincentes?

En el plano de los hechos, como ante el juicio de la mujer adúltera, cualquier solución que se proponga puede ser para perjuicio propio y de la víctima, tal vez por eso Jesús no aborda el asunto en términos legales, sino que encamina la salida por el lado práctico y por el de la interpelación hacia quien tiene el poder de arrojar la primera piedra. Nuestro argumen- 
to también, como en el caso de Jesús puede ser paliativo, momentáneamente eficiente en tanto ponemos el foco sobre el rescate de la víctima, pero queda aún el andamiaje del sistema que seguirá matando, robando, esclavizando hasta tanto podamos robustecer el poder liberador de nuestra dignidad y de nuestra verdad.

\section{Conclusión}

La comunidad de Juan representada en el relato ha hecho una clara ruptura y ha entrado en conflicto en sus propias bases judías. Ha enfrentado agudamente a sus adversarios y conoce bien cuáles serán las consecuencias, nunca menores a la suerte de su Mesías.

Así también Sonia, y lo que su discurso representa, nos coloca en el lugar incómodo, con la misión de elaborar también un pensamiento incómodo y un actuar consecuente, permanentemente provocativo a la sociedad y especialmente dirigido a quienes tienen el poder de cambiar las cosas. ¿Seremos capaces de permanecer, $\mu \varepsilon \rho 0$, en esta Palabra y esta actitud, la que confiesa nuestra fe?

El evangelio es un anuncio humanizador y dignificador para todo ser humano, en especial para los más pobres y necesitados que no pueden esperar más. El llamado de Sonia nos interpela, como en el juicio a la mujer adúltera, el llamado es a una politicidad creyente que sea menos principista y más pragmática, menos religiosa y más efectiva. El tiempo es muy corto y la situación es demasiado grave. Las piedras están sobre nuestra cabeza.

\section{Referencias}

AGUSTÍN. In Ioannis Evangelium tractatus. Tr 33:4-8 Disponible en: https://www.augustinus.it/spagnolo/commento_vsg/index2.htm Visitado el: 30 de Jun de 2019. . De adulterinis conjugiis. II, 7 Disponible en:

http://www.augustinus.it/spagnolo/connubi_adulterini/connubi_ adulterini_2_libro.htm Visitado el: 30 de Jun de 2019.

EUSEBIO. Historia Ecclesia. III. 39, 17 Disponible en:

http://escrituras.tripod.com/Textos/HistEcl03.htm

Visitado el: 30 de Jun de 2019.

SANCHEZ, Sonia. La puta esquina. Campo de concentración a cielo abierto. Buenos Aires: Ed. La Minga, 2018.

VAN TILBORG, Stefan. Comentario al Evangelio de Juan. Navarra: Verbo Divino, 2005.

HENDRIKSEN, Guillermo. El evangelio según san Juan. Grand Rapids: Subcomisión Literatura Cristiana de la lglesia Reformada, 1981.

PÉREZ MILLOS, Samuel. Comentario exegético al texto griego del Nuevo Testamento. Juan. Barcelona: CLIE, 2016. 